\section{foreign students and scientists from} coming to the United States?

Certainly, to have a robust and successful scientific enterprise you need students - you need good students, you need lots of students, you need students from diverse backgrounds, diverse points of view and so on.

I've not talked to one individual who says, "You know, I want an illegal immigrant in my laboratory." We want people who are here legally. Research is about complying.

I think it's very, very important that we are open and welcoming to individuals who share our values, who come from other countries. At the same time, we want to make sure that we're bringing in a lot of Americans.

\section{But even if students are exempted from} policies such as the travel ban against citizens of several majority-Muslim countries, these moves are still spreading fear and uncertainty. There are perceptions out there of certain things and then there are realities. The reality is the president reversed the $\mathrm{H}-1 \mathrm{~B}$ visa process where we could get many, many more people coming into the MS and
PhD fields. I thought that was fantastic.

Does it make your job as science adviser harder when Trump tweets and talks about things such as windmill noise causing cancer?

I think the president tweets what he tweets, and as president that's his thing. I think sometimes, you know, he does things in a way that he's joking around and people don't maybe realize that. I don't know.

This interview has been edited for length and clarity.

\title{
Chinese hospitals set to sell experimental cell therapies
}

\section{But some scientists are concerned that the draft regulation will endanger patients.}

\section{BY DAVID CYRANOSKI}

Clect elite hospitals in China could soon

$O$ be able to sell experimental therapies that engineer a person's own cells to treat diseases such as cancer - without approval from the nation's drug regulator. The proposal comes three years after the government shut down the sale of unapproved cell therapies following the death of a student who had received such a treatment.

The draft policy has prompted mixed responses. Some scientists say that it would give people with terminal illnesses faster access to potentially effective treatments, and that the measures would protect patients from dangerous therapies. But others question whether the regulations do enough to ensure that the treatments are safe and effective before they are sold.

In many countries, the use of cell therapies - treatments made from human cells, often from the immune system - requires approval from drug regulators, which means rigorous, costly and time-consuming clinical trials to show that they are safe and effective. Some countries have policies, such as Australia's Special Access Scheme, that allow doctors to administer unapproved cell therapies under special conditions - for example, if a patient is terminally ill.

But those are rarely used and are offered at no cost to the patient, says Rajiv Khanna, a cancer immunologist at QIMR Berghofer Medical Research Institute in Brisbane, Australia. "I am not aware of any regulatory system where top hospitals can offer cellular therapies for commercial gain on their own discretion," he says.

Under China's draft policy, which the health ministry released in March, select hospitals would be allowed to sell these therapies without testing them in large numbers of people. The proposal is expected to come into effect within the next few months.

"The regulation will promote innovation and industry in cell therapy, which will eventually benefit patients," says cancer immunologist Ma Jie, director of the biotherapy centre at Beijing Hospital.

Bruce Levine, a cancer researcher at the
University of Pennsylvania in Philadelphia, says the proposed regulations are a step in the right direction, but he questions whether these select hospitals are prepared for the potential dangers of cell therapies.

One type of cell therapy that has drawn a lot of attention lately is immunotherapy, in which immune cells are engineered, often to target cancerous cells that otherwise evade the body's defence system. These have helped some people to make surprising recoveries.

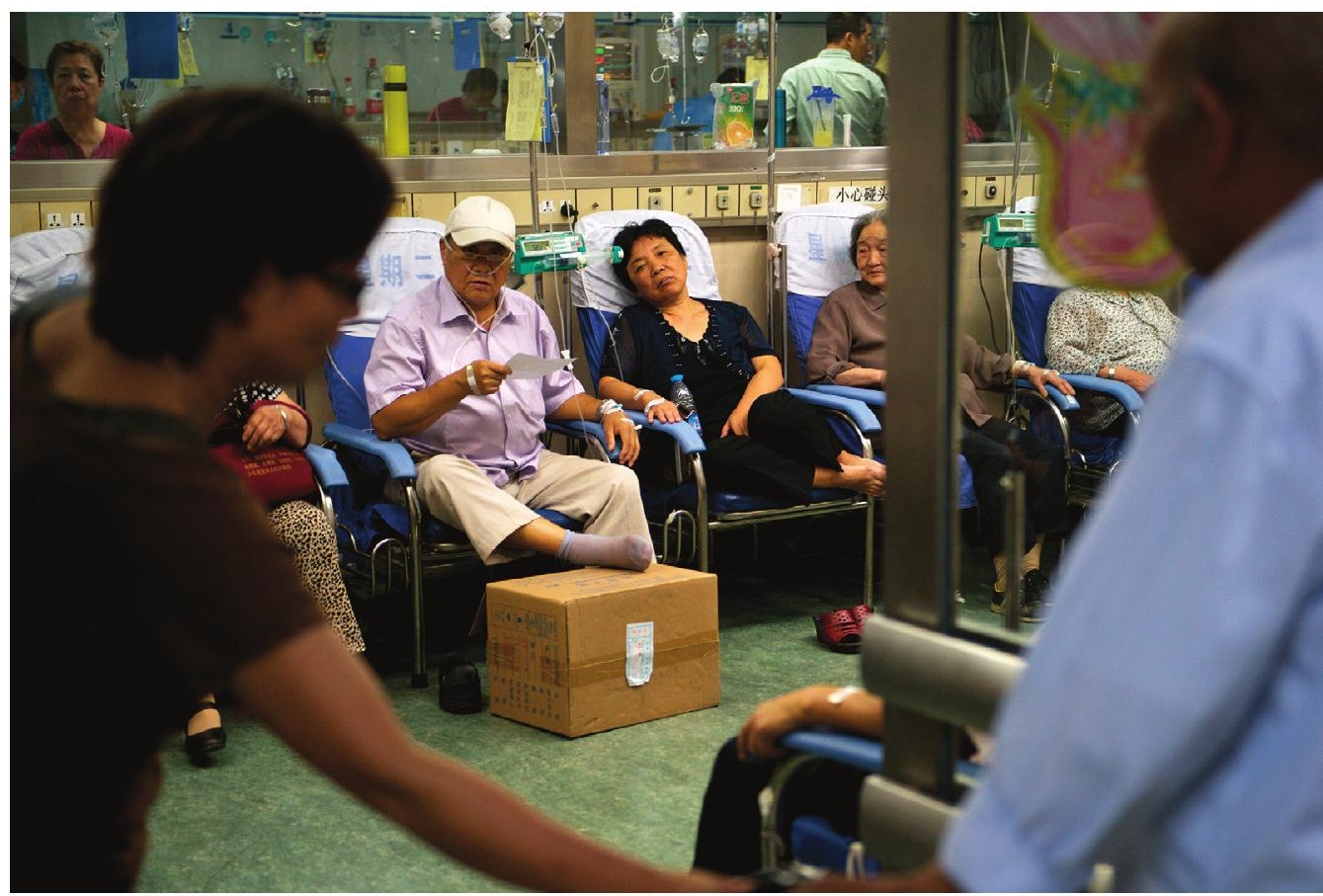

Access to cell therapies in China has been restricted since 2016 . 
But the excitement around cancer immunotherapies - two researchers won a Nobel prize last year for pioneering them - has been tempered after several participants in US clinical trials died from side effects. Regulators around the world have moved slowly to approve the treatments for sale. The US Food and Drug Administration has approved only three cancer immunotherapies so far, and the Chinese drug regulator has approved none.

Before 2016, Chinese regulations for the sale of cell therapies were ambiguous, and many hospitals sold the treatments to patients while safety and efficacy testing was still under way. Ren Jun, an oncologist at the Beijing Shijitan Hospital Cancer Center, estimates that roughly one million people paid for such procedures.

But the market came under scrutiny when it was revealed that a university student with a rare cancer had paid more than 200,000 yuan (US\$30,000) for an experimental immunotherapy, after seeing it promoted by a hospital on the Internet. The treatment was unsuccessful, and the student later died. The government cracked down on hospitals selling cell therapies - although clinical trials in which participants do not pay for treatment were allowed to continue.

\section{GATHERING EVIDENCE}

Under the proposed regulations, roughly 1,400 elite hospitals that conduct medical research, known as Grade 3A hospitals, would be able to apply for a licence to sell cell therapies, after proving that they have expertise in processing the cells and running clinical trials.

Once the hospital was licensed, its review board would oversee clinical research of experimental therapies, with participants who did not pay. If the board were to decide that these investigations had produced enough evidence that a therapy was safe and effective, the hospital would be able to start selling it.

Ren is confident that the measures would prevent treatments of unknown quality being promoted and sold.

But not everyone agrees. "The proposed regulation is a bad idea," says Michele Teng, who studies cancer immunotherapy at QIMR Berghofer. "It is critical that any new cellular therapy to be administered into patients demonstrates its safety and efficacy in phase III efficacy trials."

Having large, well-funded facilities and trained medical staff is not an adequate substitute for well-designed studies to determine whether a treatment is efficacious or not, says Douglas Sipp, who studies cell-therapy policies at the RIKEN Center for Biosystems Dynamics Research in Kobe, Japan.

The rules could even dissuade companies from doing rigorous studies, he says..

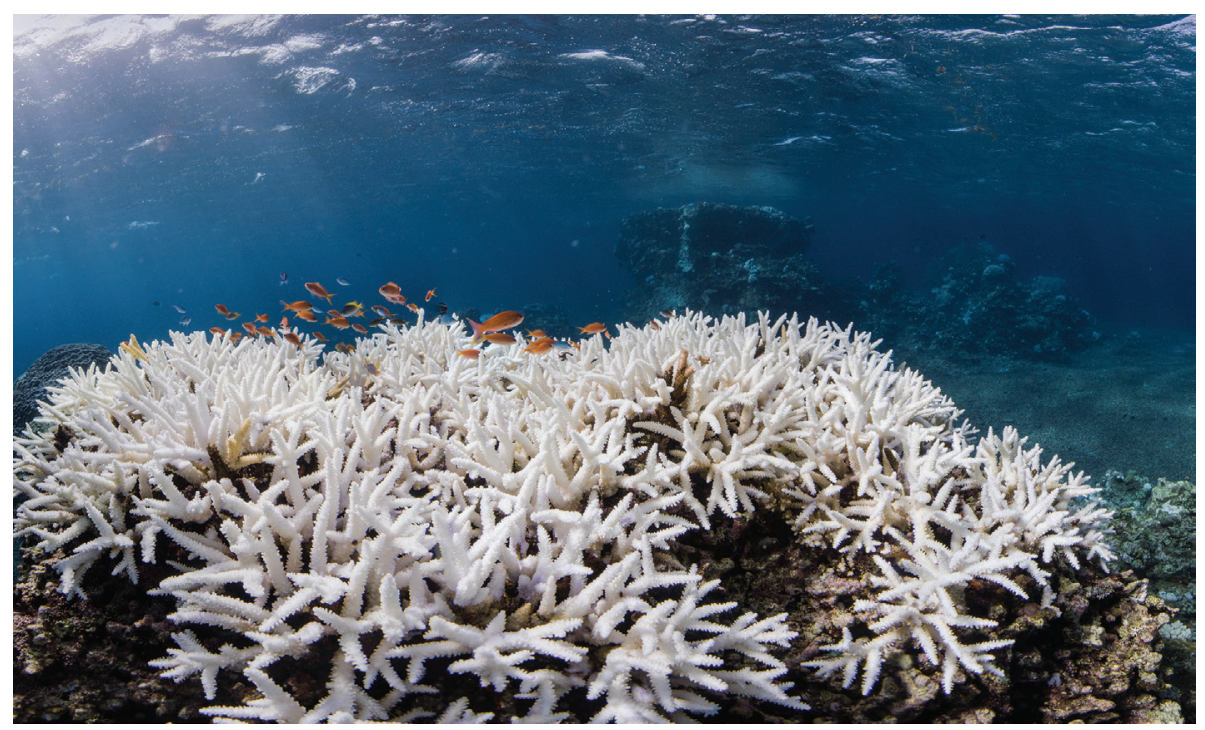

Habitats such as coral reefs have been hit hard by pollution and climate change.

BIODIVERSITY

\section{One million species face extinction}

\section{Landmark United Nations report finds that human activities threaten ecosystems around the world.}

\section{BY JEFF TOLLEFSON}

T $\mathrm{p}$ to one million plant and animal species face extinction, many within decades, because of human activities, says the most comprehensive report yet on the state of global ecosystems.

The rate of species extinctions is already tens to hundreds of times higher than the average across the past ten million years. Without drastic action to conserve habitats, the extinction rate will only increase, says a United Nationsbacked panel called the Intergovernmental Science-Policy Platform on Biodiversity and Ecosystem Services (IPBES).

About $75 \%$ of land and $66 \%$ of ocean areas have been "significantly altered" by people, driven in large part by agriculture, according to a summary of the work, released on 6 May (see go.nature.com/2v4zbn9). The loss of species and habitats poses as much a danger to life on Earth as climate change does, the IPBES report says.

The analysis distils findings from nearly 15,000 studies and government reports, integrating information from the natural and social sciences, Indigenous peoples and traditional agricultural communities. The report is the first major international appraisal of biodiversity since 2005. Representatives of 132 governments met last week in Paris to finalize and approve it.

"We have never had a single unified statement from the world's governments that unambiguously makes clear the crisis we are facing for life on Earth," says Thomas Brooks, chief scientist at the International Union for Conservation of Nature in Gland, Switzerland, who helped to edit the report. "That is really the absolutely key novelty that we see here."

Without "transformative changes" to the world's economic, social and political systems to address this crisis, the IPBES panel projects that major biodiversity losses will continue to 2050 and beyond.

The analysis, which will be released in full later this year, also inextricably links biodiversity loss and climate change. An estimated $5 \%$ of all species would be threatened with extinction by $2{ }^{\circ} \mathrm{C}$ of warming above pre-industrial levels - a threshold that the world could breach in the next few decades, unless greenhouse-gas emissions are drastically reduced.

The biodiversity crisis should be at the top of the global agenda alongside climate, said Anne Larigauderie, IPBES executive secretary, at a 6 May press conference in Paris. "We can no longer say that we did not know," she said.

Brooks says that the IPBES report will help to set the agenda when governments negotiate conservation goals for the next decade at the UN Convention on Biodiversity next year. 